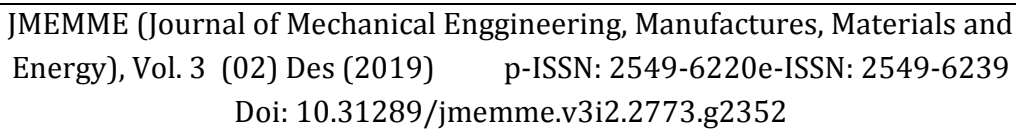

JMEMME (Journal of Mechanical Engineering, Manufactures, Materials and Energy)

\title{
ANALISIS PERBANDINGAN EFISIENSI KERJA MESIN BENSIN PADA MOBIL TAHUN 2000 SAMPAI TAHUN 2005 DAN MOBIL TAHUN 2018 SERTA PENGARUH TERHADAP KONSUMSI BAHAN BAKAR DAN CARA PERAWATANNYA SEBAGAI REKOMENDASI BAGI KONSUMEN
}

\author{
Khairuddin Tampubolon*, Faimal Rivai Koto \\ Program Studi Teknik Mesin, Universitas Pembinaan Masyarakat Indonesia \\ Diterima: 05-08-2019 ; Disetujui: 13-11-2019 ; Diterbitkan: 30-12-2019 \\ *Corresponding author: khoir.tb@gmail.com
}

\begin{abstract}
Abstrak
Pada umumnya, pengetahuan masyarakat tentang mesin mobil bekas dan mobil baru masih sangat terbatas. Hal ini disebabkan kurangnya informasi yang akurat mengenai cara ataupun teknik perawatan yang disampaikan baik dari fabrikan maupun distributor kendaraan-kendaraan tersebut. Oleh karena itu, peneliti tertarik melakukan penelitian dengan tujuan untuk: 1) menganalisis besarnya efisiensi kerja mesin mobil bensin tahun 2000 s.d. 2005 dan mobil tahun 2018 serta pengaruhnya terhadap konsumsi bahan bakar dan cara perawatannya, dan 2) memberikan informasi kepada konsumen tentang efisiensi kerja mesin mobil bensin bekas dan mobil bensin baru, pengaruhnya terhadap konsumsi bahan bakar dan cara perawatannya. Subjek dalam penelitian ini adalah mesin mobil bensin bekas tahun 2000 s.d. 2005 dan mesin mobil bensin baru 2018. Sebagai mitra adalah PT. Astra International tbk Daihatsu, Jl..M.Raja no.170 Medan. Setelah melakukan survey lokasi, verifikasi izin, waktu dan jadwal penelitian, kemudian akan dilakukan pengumpulan data dengan metode komparatif melalui pengujian variabel dan membandingkannya dengan angka korelatif indeks " $r$ ". Luaran penelitian ini yaitu: 1 . Akan dikirim ke salah satu jurnal nasional Terakreditasi . 2. Dijadikan buku Ajar . 3. Dipublikasikan ke Media cetak lokal. Sedangkan Tingkat Kesiapterapan Teknologinya berupa data hasil penelitian yang akan memberikan kontribusi terhadap konsumen.

Kata Kunci: Efisiensi, Emisi Gas Buang, Bahan Bakar, Perawatan dan Konsumen
\end{abstract}

\begin{abstract}
In general, public knowledge about used car engines and new cars is still very limited. This is due to the lack of accurate information about the way or maintenance techniques delivered both from the manufacturer and distributor of these vehicles. Therefore, researchers interested in conducting research with the aim to: 1) analyze the magnitude of the work efficiency of gasoline car engines in 2000 s.d. 2005 and 2018 cars and their effects on fuel consumption and how to treat them, and 2) provide information to consumers about the working efficiency of used gasoline car engines and new gasoline cars, their effects on fuel consumption and how to maintain them. The subject in this study was a used gasoline car engine from 2000 to.d. 2005 and the new gasoline car engine 2018. As a partner is PT. Astra International tbk Daihatsu, Jl..M.Raja no.170 Medan. After conducting a location survey, verification of permits, time and research schedule, data will be collected using the comparative method through testing variables and comparing them with correlative figures of the " $r$ " index. The outputs of this research are: 1. Will be sent to one of the Accredited national journals. 2. Used as a teaching book. 3. Published to local print media. While the level of technological readiness is in the form of research data that will contribute to consumers
\end{abstract}

Keywords: Efficiency, Exhaust Emissions, Fuel, Maintenance and Consumers 
JMEMME (Journal of Mechanical Enggineering, Manufactures, Materials and Energy), 3 (o2) (2019): 76-83

How to Cite: Tampubolon, K., 2019, Analisis Perbandingan Efisiensi Kerja Mesin Bensin Pada Mobil Tahun 2000 Sampai Tahun 2005 Dan Mobil Tahun 2018 Serta Pengaruh Terhadap Konsumsi Bahan Bakar Dan Cara Perawatannya Sebagai Rekomendasi Bagi Konsumen, JMEMME (Journal of Mechanical Enggineering, Manufactures, Materials and Energy), 3(02): 76-83 
Tampubolon, K., Analisis Perbandingan Efisiensi Kerja Mesin Bensin Pada...

\section{PENDAHULUAN}

Pada saat ini, perkembangan teknologi dan tingkat ekonomi masyarakat indonesia semakin membaik, sehingga daya beli masyarakat terhadap mobil juga menjadi meningkat didukung oleh metode pembayarannya yang juga semakin mudah, seperti sistem cicilan/kredit. Menurut Gossen [1] terdapat dua asumsi yang mendasari seseorang untuk melakukan konsumsi, yaitu konsumsi vertikal dan konsumsi horizontal, dimana pada asumsi ini, konsumsi diartikan sebagai kebutuhan. Asumsi konsumsi vertikal adalah ketika seseorang memprioritaskan pemenuhan suatu kebutuhan pada level tertinggi sehingga ketika hal itu tercapai, maka akan menimbulkan kepuasan yang tinggi pula. Hal ini berakibat kurangnya perhatian pada kebutuhan yang lain sehingga kebutuhan yang lain akan dianggap tingkat kepuasannya rendah. Asumsi konsumsi horizontal adalah ketika seseorang memperhatikan semua kebutuhannya secara sama penting dan merata dengan memperhatikan sekaligus banyak kebutuhan. Sehingga seseorang tersebut berusaha untuk memenuhi berbagai macam kebutuhannya dan berusaha memperoleh tingkat kepuasan yang sama rata dengan semua jenis pemenuhan kebutuhan tersebut.

Kerja mesin diindikasikan dengan istilah efisiensi [2]. Lima efisiensi mesin yang penting didefinisikan sebagai berikut: (1). Efisiensi termal indikatif yaitu perbandingan energi dalam daya indikatif terhadap energi bahan bakar, (2) Efisiensi mekanis yaitu perbandingan daya efektif terhadap daya indikasi, (3)
Efisiensi termal brake adalah perbandingan energi dalam daya brake terhadap energi bahan bakar, (4) Efisiensi volumetrik adalah perbandingan udara aktual yang terhisap pada kondisi atmosfer terhadap volume langkah dari mesin, dan (5) Efisiensi relatif yaitu perbandingan efisiensi termal siklus aktual terhadap siklus ideal.

Parameter unjuk kerja mesin yang penting lainnya adalah: (1) Pemakaian bahan bakar spesifik yaitu karakteristik konsumsi bahan bakar dalam gram tiap satuan daya-jam dari mesin (gram/bhp.hr ), dan (2) perbandingan bahan bakar udara ( F/A) atau (A/F) [3]. Bagian relatif dari bahan bakar udara dalam mesin sangat penting sehubungan dengan pembakaran dan efesiensi mesin. Hal ini dinyatakan dalam perbandingan massa bahan bakar terhadap udara atau sebaliknya.

Nicolas Leonard Sadi Carnot [4] adalah seorang insinyur militer berkebangsaan Prancis telah berhasil mengungkapkan teori efesiensi kerja pada sebuah mesin/motor bakar. Carnot beranggapan bahwa semua energi yang diberikan kedalam sebuah sistem (dikenal dengan input) akan berubah menjadi energi panas dan kerja (output). Faktor-faktor yang mempengaruhi efisiensi kerja mesin yang dibahas dalam penelitian ini antara lain bahan bakar dan perawatan.

Bensin adalah salah satu jenis bahan bakar minyak yang pada umumnya digunakan sebagai sumber energi kendaraan bermotor roda dua, tiga, atau empat. Mutu bahan bakar bensin dikaitkan dengan jumlah ketukan 
(knocking) yang ditimbulkannya dan dinyatakan dengan nilai oktan. Semakin sedikit ketukan, semakin baik mutu bensin dan semakin tinggi nilai oktannya [5]. Kurang diperhatikannya proses perawatan suatu mesin disebabkan oleh besarnya dana yang dibutuhkan dan rumitnya tugas perawatan, Namun bagi kegiatan operasi perusahaan, perawatan memiliki dwi fungsi, yaitu pelaksanaan dan kesadaran untuk melakukan perawatan terhadap fasilitas-fasilitas produksi dengan prinsip perawatan adalah murah sedangkan perbaikan adalah mahal [6].

Pengertian perawatan menurut beberapa orang ahli antara lain: Sofyan Assauri [7] perawatan adalah kegiatan untuk memelihara atau menjaga fasilitas/peralatan pabrik dan mengadakan perbaikan atau penyesuaian/penggantian yang diperlukan agar supaya terdapat suatu keadaan operasi produksi yang memuaskan sesuai dengan apa yang direncanakan. Menurut Daryus A. [8] dalam buku "Manajemen Pemeliharaan Mesin" menyatakan bahwa tujuan pemeliharaan yang utama dapat didefenisikan sebagai berikut: (1) Untuk memperpanjang kegunaan asset, (2) Untuk menjamin ketersediaan optimum peralatan yang dipasang untuk produksi dan mendapatkan laba investasi maksimum yang mungkin, (3) menjamin kesiapan operasional dari seluruh peralatan yang diperlukan dalam keadaan darurat setiap waktu, dan (4) Untuk menjamin keselamatan orang yang menggunakan sarana tersebut.

Efisiensi Mesin merupakan kemampuan mesin untuk dapat mengubah energi dari bahan bakar menjadi tenaga mekanik. Rata-rata mesin-mesin modern saat ini beroperasi dengan efisiensi 20 sampai 30 persen, kemudian 70 sampai 80 persennya energi bensin dikeluarkan dari mesin yaitu sebagai panas, gesekan atau energi suara mekanik. Efisiensi mesin akan nol pada kondisi mesin tidak bergerak walau assesoris mesin sedang beroperasi seperti pompa air dan generator [9]. Faktor yang mempengaruhi efisiensi mesin adalah rasio kompresi mesin, dimana semakin tinggi rasio kompresi mesin maka semakin baik efisiensi mesin secara keseluruhan. Hal ini disebabkan kemampuan mesin untuk mengubah panas menjadi energi. Mesin bensin umumnya beroperasi maximum pada rasio kompresi antara 7:1 sampai 10:1. Selanjutnya yang mempengaruhi efisiensi mesin yaitu kemampuan mesin untuk menyerap jumlah oksigen, oleh karena itu nitrous oksigen ditambahkan kedalam sistem pembakaran mesin bensin sehingga lebih banyak bahan bakar yang terbakar. Bensin dengan oktan lebih tinggi akan memungkinkan mesin untuk beroperasi dengan rasio kompresi yang lebih tinggi. Bahan bakar seperti nitrometana menghasilkan oksigen, sehingga menciptakan tenaga mesin lebih besar akibat lebih banyak bahan bakar yang terbakar.

Penerapan standar emisi gas buang Euro 4 di Indonesia berdasar Peraturan Menteri Lingkungan Hidup dan Kehutanan Republik Indonesia No. P.20/MENLHK/SETJEN/KUM.1/3/2017 tentang Baku Mutu Emisi Gas Buang Kendaraan Bermotor Tipe Baru Kategori M, Kategori N, dan Kategori 0 [10]. Dalam 
peraturan emisi gas buang Euro 4 ini yang dimaksud kategori $M$ adalah kendaraan bermotor untuk angkutan orang $\mathrm{N}$ untuk angkutan barang, dan $\mathrm{O}$ Buat kendaraan bermotor penarik gandengan. Dengan berlakunya Emisi Gas Buang Euro 4 ini, mobil baru yang dijual di Indonesia mesti memenuhi standar nilai baku mutu emisi gas buang sesuai Euro 4. Baku mutu emisi gas buang kendaraan bermotor adalah batas maksimum zat atau bahan pencemar yang boleh dikeluarkan langsung dari pipa gas buang kendaraan bermotor. Euro 4 ini mensyaratkan batas emisi karbon monoksida (CO) $1 \mathrm{~g} / \mathrm{km}$, hidrokarbon (HC) $0,1 \mathrm{~g} / \mathrm{km}$, nitrogen oksida 0,08 g/km untuk mesin bensin. Sementara batasan Euro 4 untuk mesin diesel adalah CO 0,50 g/ km, HC+NOx 0,30 g/km, NOx 0,25 g/km, dan Particulate Matter (PM) 0,025 g/km.

Kategori M (angkutan orang) mesin bensin dan diesel dengan gross vehicle weight $\leq 2,5$ ton. Untuk kendaraan penumpang mesin bensin dengan gross vehicle weight $\leq 2,5$ ton emisi maksimum Karbon Monoksida (CO) 1,0 gram $/ \mathrm{km}$, Hidrokarbon (HC) 0,1 gram $/ \mathrm{km}$, dan Nitrogen Oksida (NOx) 0,08 gram/km. Sementara untuk mobil penumpang mesin diesel gross vehicle weight $\leq 2,5$ ton emisi maksimum CO 0,5 gram $/ \mathrm{km}$, NOx 0,25 gram/km, HC+NOx 0,30 gram $/ \mathrm{km}$, dan Particulate Matter (PM) 0,025 gram $/ \mathrm{km}$.

Penelitian ini menggunakan metode komparatif, yaitu penelitian yang bersifat membandingkan data hasil pengukuran. Penelitian ini dilakukan untuk membandingkan persamaan dan perbedaan dua atau lebih fakta-fakta dan sifat-sifat objek yang diteliti berdasarkan kerangka pemikiran tertentu. Pada penelitian ini variabelnya masih mandiri tetapi sampel-sampelnya lebih dari satu atau dalam waktu yang berbeda. Menurut Nazir [11] penelitian komparatif adalah sejenis penelitian deskriptif yang ingin mencari jawaban secara mendasar tentang sebab-akibat, dengan menganalisis faktor-faktor penyebab terjadinya ataupun munculnya suatu fenomena tertentu. Jadi penelitian komparatif adalah jenis penelitian yang digunakan untuk membandingkan antara dua kelompok atau lebih dari suatu variabel tertentu.

Tujuan penelitian ini ialah untuk: (1) menganalisis besarnya efisiensi kerja mesin mobil bensin bekas dan mobil baru serta pengaruh terhadap konsumsi bahan bakar dan cara perawatannya, dan (2) memberikan informasi kepada konsumen tentang efisiensi kerja mesin mobil bekas dan mobil baru serta pengaruh terhadap konsumsi bahan bakar dan cara perawatannya.

Secara teoritis, penelitian ini memberikan manfaat menambah perbendaharaan baru tentang analisis perbandingan efisiensi kinerja mesin mobil bensin bekas dan mobil baru, diharapkan memberikan informasi tentang pengaruh efisiensi kerja mesin terhadap konsumsi bahan bakar dan cara perawatan mobil. Secara praktis, penelitian ini memberikan manfaat menjadi masukan ketika akan membeli mobil dan cara perawatannya, dapat digunakan sebagai masukan tentang minat dan kemampuan konsumen (dealer), dan bagi pemerintah diharapkan dapat membuat program 
pengaturan standarisasi kelayakan pemakaian mobil bekas.

\section{METODE}

Penelitian ini dilakukan di PT Astra International Tbk Daihatsu, Jl. S.M.Raja no.170 Medan. Adapun waktu penelitian dimulai pada awal Januari 2019 sampai dengan akhir Desember 2019. Pada penelitian ini, subjek penelitiannya adalah enam mobil bensin tahun 2000 sampai dengan 2005 dan satu mobil bensin tahun 2018 .

Test Pemakaian Bahan Bakar dilakukan dengan bantuan alat Fuel Consumption yang menggunakan sumber daya dihubungkan dengan baterai mobil dan selang dihubungkan ke aliran bahan bakar mobil (gambar 1). Pengetesan emisi gas buang menggunakan alat test emisi gas buang jenis Merk Qrotech-402 (gambar 2).

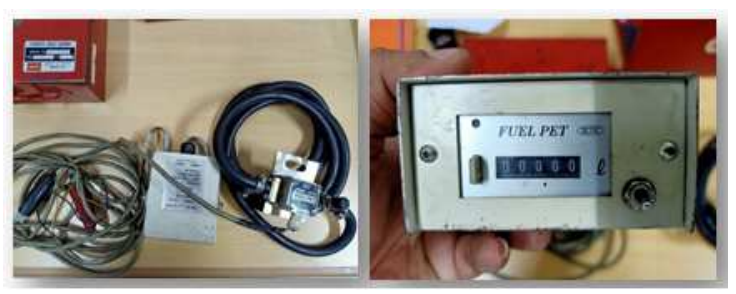

Gambar 1. Alat ukur konsumsi bahan bakar (fuel consumtion): (a) kabel sensor, dan (b) alat pembacaan sensor

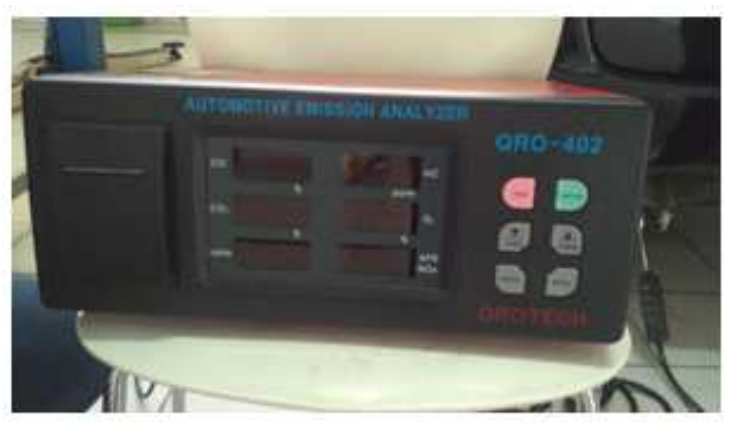

Gambar 2. Alat test emisi gas buang jenis Qrotech-402

\section{HASIL DAN DISKUSI Hasil Rancangan BR}

Setelah melakukan test drive terhadap tujuh mobil Daihatsu dengan berbagai jenis dan tahun produksi berbeda dan kondisi jalan tol dan jalan macet diperoleh data konsumsi bahan bakar untuk kondisi jalan dalam kota seperti diperlihatkan pada tabel 1 dan kondisi luar kota diperlihatkan pada tabel 2. Hasil pengetesan emisi gas buang terhadap 7 mobil Daihatsu dengan berbagai jenis dan tahun produksi berbeda diperlihatkan pada tabel 3 .

Tabel 1. Hasil test drive mobil dengan kondisi jalan dalam kota macet (route SPBU 14.2021.26, Jl. S.M. Raja no. 45

Medan sampai Pelabuhan Belawan 1, ? 28 km, Periode Test: Maret s.d. Juni 2019)

\begin{tabular}{|c|c|c|c|c|c|}
\hline No & IENIS MOBII & $\begin{array}{l}\text { JARAKYANG } \\
\text { DITEMPUH }\end{array}$ & $\begin{array}{l}\text { AC DAN } \\
\text { AUDIO HDUP }\end{array}$ & $\begin{array}{l}\text { TANPABEAAN } \\
\text { BAWAAN }\end{array}$ & $\begin{array}{c}\text { KONSUMSI BAHAN BAKAR/(km/1) } \\
\text { DALAM KOTA/ MACTT }\end{array}$ \\
\hline 1 & Taruna cx Tahun 2000 karbutor & $28 \mathrm{~km}$ & $\mathrm{v}$ & $\mathrm{v}$ & $1: 5$ \\
\hline 2 & Taruna Q EFI (injection) Tahun 2001 & $28 \mathrm{~km}$ & $\mathrm{v}$ & $\mathrm{v}$ & $1: 7$ \\
\hline 3 & Taruna FGX Tahun 2002 & $28 \mathrm{~km}$ & $\checkmark$ & $\mathrm{v}$ & $1: 8$ \\
\hline 4 & Taruna FGX Tahun 2003 & $28 \mathrm{~km}$ & $\mathrm{v}$ & $\mathrm{v}$ & $1: 9$ \\
\hline 5 & Xenia Xi 1.3 manual Tahun 2004 & $28 \mathrm{~km}$ & $\mathrm{v}$ & $\mathrm{v}$ & $1: 9$ \\
\hline 5 & Xenia li Tahun 2005 & $28 \mathrm{~km}$ & $\mathrm{v}$ & $\mathrm{v}$ & $1: 10$ \\
\hline 7 & Sigra Tahun 2018 & $28 \mathrm{~km}$ & $\mathrm{v}$ & v & $1: 19$ \\
\hline
\end{tabular}

Tabel 2. Hasil test drive mobil dengan kondisi jalan luar kota jalan tol rute jalan tol Amplas ke Tebing Tinggi, ? $62 \mathrm{~km}$ (Periode uji Maret s.d. Juni 2019)

\begin{tabular}{|c|c|c|c|c|c|}
\hline No & JENS MOEII & $\begin{array}{l}\text { IARAKYANG } \\
\text { DITEMPUH }\end{array}$ & $\begin{array}{c}\text { AC DAN } \\
\text { AUOIO HIOUP }\end{array}$ & \begin{tabular}{|c|} 
TANPA BERAN \\
BAWAAN
\end{tabular} & | KONSUMSII BAHANBAKKaR/(km/l) \\
\hline 1 & Taruna $\alpha$ Tahun 2000 karbutor & $62 \mathrm{~km}$ & $\mathrm{v}$ & $\checkmark$ & $1: 10$ \\
\hline 2 & Taruna Q EA (injection) Tahun 2001 & $62 \mathrm{~km}$ & $\mathrm{v}$ & $\mathrm{v}$ & $1: 10$ \\
\hline 3 & Taruna FGX Tahun 2002 & $62 \mathrm{~km}$ & $\mathrm{v}$ & $\checkmark$ & 1:11 \\
\hline 4 & Taruna FGX Tahun 2003 & $62 \mathrm{~km}$ & $\mathrm{v}$ & $\mathrm{v}$ & $1: 13$ \\
\hline 5 & Xenia Xi 1.3 manual Tahun 2004 & $62 \mathrm{~km}$ & $\mathrm{v}$ & $\mathrm{v}$ & $1: 14$ \\
\hline 6 & Xenia il Tahun 2005 & $62 \mathrm{~km}$ & $\mathrm{v}$ & $\mathrm{v}$ & $1: 15$ \\
\hline 7 & Sigra Tahun 2018 & $62 \mathrm{~km}$ & $\mathrm{v}$ & $\mathrm{v}$ & $1: 22$ \\
\hline
\end{tabular}


Tabel 3. Hasil uji emisi gas buang (periode uji Maret s.d. Juni 2019

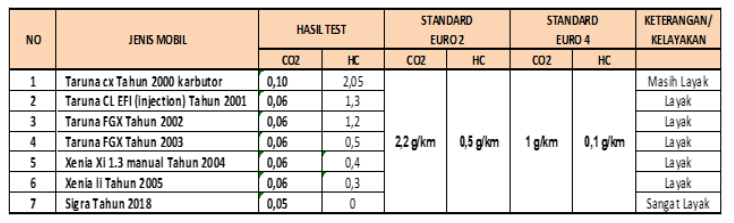

Dari hasil test emisi gas buang dapat diketahui sebagai berikut: jika gas CO tinggi, berarti pembakaran kurang sempurna akibat kurangnya udara dalam campuran dengan bahan bakar. Hasil uji ini dapat mengetahui konsumsi bahan bakar boros atau tidak, kompresi mesin bagus atau tidak, dan pengapian mobil bagus atau tidak. Adanya gas HC pada hasil pembakaran menunjukkan bahan bakar yang tidak terbakar, sehingga jika angka $\mathrm{HC}$ terlalu tinggi berarti ada busi yang tidak bagus atau koil yang tidak berfungsi. Adanya gas $\mathrm{O} 2$ atau oksigen, kalau kadar oksigennya terlalu tinggi pada hasil pembakaran berarti indikasi kebocoran sistem knalpot bocor, sementara Lambda serta AFR bisa dipakai mengukur campuran ideal bahan bakar dan udara.

\section{KESIMPULAN}

Faktor yang mempengaruhi efisiensi mesin adalah rasio kompresi mesin, dimana semakin tinggi rasio kompresi mesin maka semakin baik efisiensi mesin secara keseluruhan. Hal ini disebabkan kemampuan mesin untuk mengubah panas menjadi energi. Mesin bensin umumnya beroperasi maximum pada rasio kompresi antara 7:1 sampai 10:1. Selanjutnya yang mempengaruhi efisiensi mesin yaitu kemampuan mesin untuk menyerap Jumlah oksogen, inilah mengapa nitrous oksigen ditambahkan kedalam sistem pembakaran mesin bensin. Nitrous oxide menambahkan molekul oksigen ke dalam ruang bakar, sehingga lebih banyak bahan bakar yang terbakar. Kemudian yang mempengaruhi efisiensi mesin yaitu Jenis bahan bakar yang digunakan, Bensin dengan oktan lebih tinggi akan memungkinkan mesin untuk beroperasi dengan rasio kompresi yang lebih tinggi. Bahan bakar seperti nitrometana menghasilkan oksigen, sehingga menciptakan tenaga mesin lebih besar akibat lebih banyak bahan bakar yang terbakar. Kemudian Efisiensi Kinerja Mesin juga dipengaruhi oleh sistem Pembakaran bahan Bakar yaitu Sistem Karburator atau Sistem Efi. Efisiensi Kinerja Mesin Mobil Bekas sangat rendah dibandingkan mobil baru dan akan terus mengalami pengembangan kepada yang lebih baik dari waktu kewaktu. Pemakaian Bahan Bakar Mobil Tahun 2000 sampai dengan Tahun 2005 lebih boros jika dibandingkan dengan Mobil Tahun 2018, terutama Mesin yang masih menggunakan sistem pengapian dengan Karburator seperti Mobil tahun 2000, dari hasil uji coba yaitu 6:19 kml (untuk dalam kota macet) dan 10:22 kml (untuk Kondisi Jalan Tol). Konsumsi Bahan Bakar saat dikendarai tergantung beberapa Faktor diantaranya: Kondisi jalan yang dilalui, cara pengemudi menjaalankan kenderaan, faktor cuaca saat dikendarai yaitu semakin panas cuaca maka bahan bakar akan semakin irit. Beban yang dibawa kendaraan, fasilitas kenderaan yang diaktifkan seperti : AC, Pemutar Music dll. 
Berdasarkan hasil test emisi gas buang dapat diketahui sebagai berikut: jika CO tinggi, bisa berarti pembakaran tidak sempurna akibatnya busi mati, kesalahan firing dan sebagainya. Dari cek emisi gas buang kita bisa mengetahui bahan bakar boros atau tidak, kompresi mesin bagus atau tidak, dan pengapian mobil bagus atau tidak. Sedangkan gas HC menunjukkan bahan bakar yang tidak terbakar. Jika angka HC terlalu tinggi berarti kelebihan bahan bakar seperti banjir campuran gemuk. Lalu ada 02 atau oksigen, kalau kadar oksigennya terlalu tinggi pada hasil pembakaran berarti indikasi kebocoran sistem knalpot bocor, Sementara Lambda serta AFR bisa dipakai mengukur campuran ideal bahan bakar dan udara. penerapan standard emisi gas buang dengan EURO 4, masih belum bisa terlaksana di Indonesia, karena bahan bakarnya belum memenuhi Standard EURO 4, yaitu adapun dikarenakan tidak tersedia reference fuel di Indonesia, dapat digunakan BBM untuk kendaraan dengan penggerak penyalaan dengan ketentuan minimal RON (research octane number) 95. RON 95 itu dianggap mempunyai kandungan timbal $(\mathrm{Pb})$ maksimal 0,013 g/l dan kandungan sulfur maksimal 500 ppm. Sedangkan untuk mesin kendaraan kompresi (diesel) dengan parameter bahan bakar Cetane Number minimal 51, kandungan sulfur maksimal 500 ppm.

\section{UCAPAN TERIMA KASIH}

Ucapan terima kasih kepada Pimpinan PT Astra International tbk Daihatsu Jl. S.M. Raja no.170 Medan yang telah memberikan bantuan fasilitas penelitian berupa alat uji fuel consumption dan emisi gas buang selama proses penelitian ini berlangsung.

\section{REFERENCES}

[1] J. Stanford, Economics for Everyone, ist ed. London: Pluto Press, 2008.

[2] J. D. Osorio and A. Rivera-alvarez, "Efficiency enhancement of sparkignition engines using a Continuous Variable Valve Timing system for load control," Energy, 2018.

[3] F. A.S. Silitonga, H.H. Masjuki, Hwai Chyuan Ong, A.H. Sebayang, S. Dharma, W.-H. Kusumo, J. Siswantoro, Jassinnee Milano, Khairil Daud, T.M.I. Mahlia, and B. S. Chen, "Evaluation of the engine performance and exhaust emissions of biodiesel-bioethanoldiesel blends using kernel-based extreme learning machine," Energy, 2018.

[4] M. Thirumaleshwar, Applied Thermodynamics Software Solutions Applied Thermodynamics :, ist ed. New York: McGraw-Hill, 2014.

[5] R. A. Barreto, "Fossil fuels, alternative energy and economic growth," Econ. Model., vol. 75, no. May, pp. 196-220, 2018.

[6] M. Toma and C. Bobâlc, "Research on Drivers ' Perception on the Maintenance of Air Filters for Internal Combustion Engines," vol. 22, no. October 2015, pp. 961-968, 2016.

[7] R. Keith Mobley, MAINTENANCE FUNDAMENTALS, 2nd ed. Oxford: Elsevier, 2004.

[8] ASYARI DARYUS, Manajemen pemeliharaan mesin, ist ed. Jakarta: UNIVERSITAS DARMA PERSADA, 2007.

[9] A. BROWN, TECHNOLOGIES AND APPROACHES TO MEDIUM- AND HEAVY-DUTY VEHICLES, 1st ed. Washington DC: THE NATIONAL ACADEMIES PRESS, 2010.

[10] M. L. H. D. K. R. INDONESIA, BAKU MUTU EMISI GAS BUANG KENDARAAN BERMOTOR TIPE BARU KATEGORI M, KATEGORI N, DAN KATEGORI O. Indonesia, 2017, pp. 1-26.

[11] R. Kumar, RESEARCH METHODOLOGY, 3rd ed. Los Angeles: SAGE Publications Ltd, 2011. 